Cuadernos de Historia del Derecho

ISSN: $1133-7613$

http://dx.doi.org/10.5209/CUHD.61876

\title{
El suicidio en la práctica judicial moderna $(*)$
}

\author{
Victoria Sandoval Parra ${ }^{1}$
}

Recibido: 07 de abril de 2018 / Aceptado: 21 de mayo de 2018

Resumen. El trabajo analiza, en un proceso criminal de finales del siglo XVI, las alteraciones que experimenta en la práctica judicial la teoría del crimen de suicidio elaborada por los juristas y teólogos modernos, particularmente por lo que se refiere a sus causas, medios probatorios y penas.

Palabras clave: Suicidio; Historia del Derecho penal; Doctrina jurídica; Práctica judicial.

\section{[en] Suicide in modern court practice}

Abstract. The paper analyzes, in a criminal process from the late sixteenth century, the alterations that experiments the theory of suicide as a crime -elaborated by jurists and theologians during the Modern Age - in the judicial practice, particularly with respect to its causes, evidences and punishments.

Keywords: Suicide; History of Criminal Law; Judicial doctrine; Judicial practice;

\section{[fr] Le suicide dans la pratique judiciaire moderne}

Résumé. D'après une poursuite criminelle de la fin du XVI e siècle on analyse les changements d'expérience dans la pratique judiciaire, la théorie du crime de suicide élaboré par des juristes et des théologiens modernes, en particulier en ce qui concerne les causes, les formes de preuve et les peines.

Mots clé : Suicide; Histoire du droit pénal; doctrine juridique; pratique judiciaire.

Sumario: I. Las claves de la teoría jurídica moderna del suicidio. II. Causas y penas del suicidio. 1. Alteraciones judiciales en las causas del suicidio. 1.1. Del tedio vital a la demencia. 1.2. De la conciencia del crimen o miedo a la pena a la conciencia o miedo de la responsabilidad civil. 2. Problemas judiciales en las penas del suicidio. 2.1. Práctica de la sepultura. 2.2. Práctica de la confiscación de bienes. III. La prueba del suicidio. 1. Prueba de la cualificación del crimen. 2. Circunstancias probatorias. 2.1. Modo de la muerte. 2.2. Conato o continuidad en el acto de suicidio. 2.3. Persistencia temporal de la demencia. 2.4. Inventario de documentación obligacional. 2.5. Fama del reo.2.5. Tipo de sepultura. 2.6. Testimonios, notoriedad y otras pruebas. IV. Las sentencias.

Cómo citar: V. Sandoval Parra (2018). «El suicidio en la práctica judicial moderna», Cuadernos de Historia del Derecho, XXV, 2018, 113-136.

Universidad de Murcia

vsp46180@um.es 


\section{Las claves de la teoría jurídica moderna del suicidio}

El pleito litigado entre el fiscal acusador, don Gregorio de Tovar, y Diego López de Uceda, en representación de su hijo, Juan López de Uceda, vecinos de la villa de Talavera de la Reina, por un posible crimen de suicidio de éste último, nos sitúa a finales del siglo XVI, concretamente en $1589^{2}$. Época y fecha son significativas porque la doctrina teológica, moral y jurídica consolida entonces una teoría plena sobre la naturaleza del crimen de suicidio ${ }^{3}$ que parte, en líneas generales, de los presupuestos formulados por Santo Tomás de Aquino advirtiendo su naturaleza de grave injuria contra Dios, la inclinación natural y la comunidad. El suicidio es un pecado mortal que daña la caridad que el hombre debe observar respecto de sí mismo, pero también constituye una vulneración de la justicia no sólo divina, sino propia del Derecho positivo. Con la preocupación constante de los doctores por el dolo como esencia criminal, los motivos que guíen al suicida a la comisión de su acción siempre serán contrastados con su malignus animus, sin que quepa argumento alguno que justifique su acción, puesto que precisamente lo que el malignus animus ha provocado con el suicidio es la pérdida del cuerpo y sobre todo del alma, y en consecuencia la imposible esperanza de llegar a Dios. No obstante, esta valoración objetiva del acto suicida a la que conduce la malignidad del ánimo no empece el interés de la doctri-

(*) Este trabajo pertenece al Proyecto de investigación titulado Literatura del crimen: doctrina jurídica y crónica social (siglos XVI-XX), ref. DER2015-64627-P, financiado por el Ministerio de Economía y Competitividad. «Ejecutoria del pleito litigado por el fiscal del rey con Diego López de Uceda, como padre de Juan López de Uceda, su hijo, difunto, vecinos de Talavera de la Reina (Toledo), sobre posible suicidio de éste último»: Archivo de la Real Chancillería de Valladolid, Registro de ejecutorias, caja 1696.28.

3 La síntesis de la teoría clásica del suicidio que aquí se desarrolla tiene como referencia la lectura de Pedro de Aragón, De iustitia et iure, Salamanca, aput Guillermun Foque, 1590, pp. 356-371; Martín de Azplicueta, Manual de confesores y penitentes que clara y brevemente contiene la universal y particular decisión de quasi todas las dudas que en las confessiones suelen ocurrir de los pecados, absoluciones, restituciones, censuras, \& irregularidades, Salamanca, casa de Antrea de Portonariis, 1557, pp.150-155; Iacobus de Bello Visu, Avrea practica criminalis, vetusissimi cum practici, tum iuris interpretis, ex recognitione, Colonia, a apud Maternum Cholinum, 1580, p. 591; Benedicto Carpzov, Practicae Novae Imperiales saxonicae rerum criminalium, Pars I, vittebergae, Sumptibus Haeredum D. tobiae Mevii, \& Elerdi Schumacheri, 1670, pp. 9-15; Iodoco Damhouder, Praxis Rerum Criminalium, Antuerpia, Apud Ioannem Bellerum, sub insigni Falconis, 1555, pp. 310-314; Rerum Criminalium Praxes et Tractatus ómnium nobiliorum, qui ad hunc diem exiverunt iureconsultorum, Francofurti,, apud Ioan. Wechelum Impens. Sigis. Feyrab., 1587, pp. 130-131; Antonio Diana, Resolutionum moralium, Pars V, Matriti, ex typographia Mariae de Quiñones, 1640, pp.187-192; Prospero Farinacio, Praxis, et theoricae criminalis, Pars Quarta, Editio postrema recens ab Auctore recognita, locupletata, \& mendis expurgata, Lugduni, Sumptibus Iacobi Cardon, 1631, pp.317-329; Baltasar Gómez de Amescua, Tractatus de potestate in se ipsum, Mediolani, aput HIeronymum Bordomun, 1609, pp. 1-456; Juan Machado de Chaves, Suma moral y resumen brevissimo de todas las obras del doctor Machado, Madrid, por Andrés García de la Iglesia, 1661, pp. 141-142; Ludovico Molina, De iustitia et Iure, tomo I, Moguntiae, Excudebat Balthasar Lippius, Sumptibus Hermanni Mylii Brckm, 1614, cs. 17-18, tomo IV, cs. 551-556, 588-592; Marco Antonio Sabelli, Summa diversorum tractatumm, Tomo II, Venetiis, Apud Paulum Balleonium, 1697, pp. 280-291; Jacobo de Simancas, De catholicis institutionibus liber, ad precavendas \& extirpandas haereses admodum necessarius, Compluti, apud Andream de Angulo, 1569, fols. 70-80; Domingo de Soto, De iustitia \& iure, libri decem, excudebat Ioannes Baptista a Terranova, 1574, pp. 365-367; Alonso de Vega, Summa llamada de nueva recopilación y práctica del fuero interior, Madrid, por Luis Sánchez y a su costa, y a la de Iuan de Bari, 1606, pp. 1196-1198, 1220-1221, 323-328; Giovanni Baptista Ziletti, Consiliorum seu responsorum ad causas criminales, tomo III, Venetiis, apud Bernardinum Ziletum et frates, 1566, fols. 44-45. Para un análisis más completo sobre la teoría criminal del suicidio según la literatura jurídica durante la Edad Moderna vid. Victoria Sandoval Parra, El crimen de suicidio en la Edad Moderna. Tratamiento institucional en la literatura moral y jurídica europea, Madrid, Dykinson, 2017. 
na por una consiguiente caracterización subjetiva del suicida, pues a diferencia de cualquier otro delincuente aquél suele ocultar la precipitación de factores internos y externos que van a dar lugar a la comisión de su delito; de nuevo hay que decir que la reflexión de los doctores se esfuerza, ratificando su dogma interpretativo del suicidio, por difundir, a lo largo de esa compleja trama de circunstancias hipotéticas, una visión del suicida que haga entender con evidencia que su acto carece de legitimación moral alguna. En este mismo sentido funciona la repulsa hacia el suicidio en toda la escala de ordenamientos jurídicos; como sostiene Pedro de Aragón, el homicidio del suicida ignora a Dios en cuanto origen y conductor de la vida, ignora la naturaleza porque transforma la inclinación del hombre hacia la felicidad en una disposición que excede los límites de la capacidad de elección de la persona usurpándosela a Dios, y ofende a los miembros que conforman la comunidad al renunciar al servicio y a las justas obligaciones que corresponden a todo sujeto. Quien se mata a sí mismo quebranta el precepto sagrado del Quinto Mandamiento como sucede en la comisión de homicidio, pero si el suicidio, al igual que el homicidio, priva a la muerte de dignidad, añade una cualificación que destaca su atrocidad precisamente porque el sujeto es vencido por su misma flaqueza, por su mismo envilecimiento, y no por la violencia de un acto externo irremediable; en definitiva, el suicida se arroga un derecho que no tiene al actuar como juez de sí mismo, al condenarse y ejecutar en sí mismo la muerte, y priva a su vez a la potestad pública del ius puniendi que le corresponde.

La estructura de la teoría criminal del suicidio que la doctrina teológica y jurídica desarrolla durante los siglos XVI y XVII se basa en una definición del suicidio como un acto criminal homicida que se especifica homicidium qualificatum y cuyo agravante precisamente se deriva de la extraña posición que ocupa el sujeto que consuma el delito, al mismo tiempo criminal y víctima. El suicida se caracteriza además por su complejidad psicológica, por mucho que cualquier padecimiento o motivación de su acto tienda a ser eclipsado por la mala voluntas presumida en la comisión del crimen. El suicida, o también el que atenta contra sí mismo sin obtener el resultado esperado, permanece infame, y no conviene entrar en valoraciones particulares: fuere por el motivo que fuere, bien la conciencia de crimen y el miedo a la pena futura, bien el tedio vital, el dolor o la enfermedad, el furor o la locura, la doctrina alerta para que las matizaciones no impidan resaltar la magnitud del crimen suicida que lo convierte en un acto abominable y maligno que ha de marcar con la infamia a su ejecutor. En definitiva, la naturaleza teológico-jurídica del suicidio preserva la esencia de un pecado contrario a la caridad, entendida ésta como la virtud por la cual se ama a Dios sobre todas las cosas, perdida en el siervo Suyo que opta por matarse y priva además a la república de uno de sus miembros. De esta forma, el alejamiento definitivo de Dios no es otra cosa que una inclinación a Satanás: en esta tentación reside la naturaleza atroz del crimen en el que el pecado del suicidio consiste. Y la cualificación del crimen, moral y técnicamente, es la que impone en la práctica una forma de ejecución cualificada (y condicionada por el hecho de que en el suicidio, como es evidente, el reo ha muerto): la administración de justicia impone al suicida la misma pena que al homicida y en consecuencia lo castiga con la pena simbólica de muerte y con la efectiva confiscación de los bienes.

Ahora bien, la legislación y la doctrina jurídica elaboran, con la reconocida argumentación escolástica, una tipología del suicidio que, como se ha dicho, clasifica las posibles causas o razones que influyeron o motivaron al individuo en orden a la 
comisión de tan nefasto acto. Esta tipificación distingue dos grandes bloques fundamentales, con efectos penales sustantivos y procesales distintos en función de las características del delito; así, se diferencia entre el suicidio conscientia criminis vel metu poenae y el suicidio taedio vitae vel impatientia vel dolore, y si bien el primero atrae la condena efectiva mientras el segundo permite la hipótesis de la incapacidad de dolo, ambos parten del criterio común del suicidio como homicidio cualificado que exige prueba contra la presunción (homicida simple) de la falta de cualificación. Por otra parte, si la teoría criminal del suicidio condena la ejecución de la propia muerte en sí y de manera inmediata, también condena el atentado o conato, dada la singularidad de que sea esta la situación en la que todavía vive un criminal merecedor de pena que, de haber consumado el crimen de suicidio, habría evitado el castigo in persona con su extinción; condena el conato, por lo demás, bien sea más próximo al affectus o al effectus de la perfección del delito, como resulta propio de los crímenes atroces. Por otro lado, diversas son las situaciones afines al suicidio que permiten dudar acerca de la voluntariedad del acto suicida y que son cuestionadas por la literatura jurídica moderna para determinar su licitud o ilicitud: entre ellas, la autolesión, como la amputación deliberada de algún miembro del cuerpo, cuya afinidad con el suicidio será una constante en la medida en la que todo miembro tiene la función de contribuir a que el cuerpo humano, en su totalidad, mantenga una actividad íntegra; la intención ocasional de suicidio, como el deseo de muerte hacia uno mismo limitado a cierta situación esporádica; la autotortura, entendida como la aplicación del tormento de forma extrajudicial o privada, o las torturas purificadoras, similares a las ordalías de época medieval; asimismo, el abuso del ayuno y la abstinencia, pues si el hombre no es dueño de su vida, no es lícito acortarla con privaciones; el abuso de la caridad o el martirio; el suicidio indirecto como la muerte por inanición o la negación a tomar la medicación prescrita para la enfermedad... Variantes de un suicidio de carácter mediato, en definitiva situaciones que ponen en riesgo la vida humana y en las que la doctrina jurídica hace hincapié analizando los matices que convierten una acción lícita y aceptada en ilícita y afín al crimen suicida.

Conviene mencionar en último lugar las penas previstas por el Derecho canónico y civil para con el suicidio. El suicida ha de cumplir penitencia por el pecado mortal cometido, pues la comunidad eclesiástica lo repele, de ahí que una pena espiritual característica del suicidio sea la expulsión de la Iglesia. Por esta razón, al suicida se le deniega la sepultura eclesiástica, de manera que no es enterrado en sagrado; en general es la costumbre propia del lugar la que determina qué hacer con el cadáver. Se trata, como subraya Damhouder, de evitar respecto de quien se ha apartado definitivamente de Dios cualquier señal de condescendencia. Desde esta perspectiva punitiva, la clásica tipología jurídica que distingue entre el suicidio por conciencia de crimen o miedo a la pena, del suicidio por el tedio vital u otros condicionantes psicológicos, a los ojos de la Iglesia no adquiere relevancia sobre la afrenta gravemente injuriosa y ofensiva hacia Dios; ahora bien, la inquisición judicial que pueda determinar la presencia de deliberación o de capacidad criminal en el acto permite que, cuando no alcanza a probarse, la Iglesia opte por conceder sepultura eclesiástica, aunque mediante la celebración de un sepelio más íntimo. En el Derecho civil esta valoración de la capacidad de dolo se reproduce en la apreciación judicial, haciendo valer la tipología clásica al vincular la imposición de pena tan solo al supuesto de suicidio por conciencia del crimen o miedo de la pena; esta pena ha de ser en tal caso, como explica la doctrina jurídica, únicamente 
la confiscación de bienes, pues el ahorcamiento del cadáver es comentada como una práctica caída en desuso.

Si estas son las claves de la teoría moderna del suicidio, sin embargo sería interesante indagar sobre si la praxis judicial ordinaria se mostró fiel a esta estructura criminal recogida en la legislación y (de manera extensa y mucho más argumentada) en la doctrina jurídica, o si por el contrario se desvió en la comprensión de sus conceptos o tomando en consideración otras motivaciones criminales. Quizá convenga llamar la atención, desde este punto de vista procesal, sobre el hecho de que en el suicidio se produzca una cierta paradoja, porque si hay que presumir iuris tantum el dolo como en todo crimen en su versión simple (no en vano el suicidio se define como una modalidad de homicidio cualificado respecto del homicidio simple) y por el contrario la cualificación de premeditación ha de ser probada, sin embargo no hay un suicidio simple posible a falta de premeditación, lo que desplaza hacia esta premeditación la presunción que se deriva del acto mismo de la muerte; de la misma forma, en el suicidio no cabe, por definición, la culpa ni el caso fortuito. Así pues, en el enfrentamiento procesal la acusación debe probar una premeditación cuya cualificación parece derivarse directamente de la hominis caedo (en vez de sobreponerse a una modalidad simple del crimen), en tanto que la parte acusada puede probar contra la misma base del dolo simple presunto en función de las cualidades delictivas o de pruebas que convenzan de la incapacidad de dolo del reo.

La significativa ejecutoria que analizamos en estas páginas refleja el pleito que enfrenta al fiscal del rey, como parte acusadora, con Diego López de Uceda como representante de la parte acusada, su hijo Juan López de Uceda, por un posible suicidio de éste acaecido en la villa de Talavera de la Reina el 30 de agosto de 1589. El pleito es sustanciado por la justicia local, que ordena como medida cautelar, durante la información sumaria, el secuestro y el embargo de los bienes de Juan López de Uceda, así como el enterramiento del cadáver en un hoyo de la otra parte del río Tajo, para continuar con las averiguaciones e investigaciones correspondientes, al cabo de las cuales dará comienzo el juicio plenario, trasladándose a la parte acusada la acusación en la que el promotor fiscal, con el argumento de que Juan López de Uceda se ahorcó deliberadamente ante la imposibilidad de hacer frente a sus deudas, pide la confiscación de bienes del suicida. La contestación alega un conjunto de consideraciones entre las que destaca la condición católica practicante del reo, la ausencia de testigos que presenciasen el acto, la posibilidad de un homicidio violento efectuado por terceros, o una supuesta y continua enajenación mental sobrevenida unos días antes de la comisión del acto. Tras la declaración de testigos, se decreta el embargo de bienes y el inventario de documentos de Juan López, para continuar con la investigación y determinar si, ciertamente, tal y como sostiene el promotor fiscal, eran ciertas las deudas que mantenía el difunto. Finalmente, el alcalde mayor dicta sentencia condenatoria y ordena la confiscación de los bienes de Juan López de Uceda. Notificada la sentencia a las partes, Diego López de Uceda interpone recurso de apelación contra el fallo ante los alcaldes mayores de la Real Chancillería de Valladolid, solicitando la revocación de la sentencia por considerarla injusta y alegando, de nuevo, que fue la enajenación mental que padecía el reo la causa fundamental de su ahorcamiento, y añadiendo una referencia a la decisión del juez eclesiástico de enterrar en sagrado el cuerpo de su hijo. Trasladado el recurso al procurador fiscal, este insiste en considerar el suicidio deliberado. El tribunal dicta entonces sentencia firme revocando el fallo pronunciado por el alcalde mayor de la villa de Talavera de la Reina y, por lo 
tanto, la parte acusada queda absuelta. El fiscal de la Real Chancillería de Valladolid interpondrá todavía un recurso de súplica, asegurando que el crimen se encontraba plenamente probado, que eran falsas las declaraciones de los testigos y las pruebas que la parte acusada había presentado así como el estado de enajenación mental y furor que la parte contraria defendía como motivo del ahorcamiento. Aceptado el recurso y sin la práctica de nuevas pruebas, finalmente el tribunal de la Real Chancillería de Valladolid resuelve confirmando la sentencia de vista absolutoria.

\section{Causas y penas del suicidio}

\section{Alteraciones judiciales en las causas del suicidio}

\subsection{Del tedio vital a la demencia}

La literatura jurídica moderna hace hincapié en un tipo de suicidio motivado en causas fundamentalmente ligadas al tedio vital y que aglutinarían toda una serie de condicionantes psicológicos próximos a la melancolía, la enfermedad o la incapacidad para soportar el dolor. Quizá la ambigüedad de estos factores explica que, como sabemos, la doctrina insista en que, por muy profundo que pueda ser el sufrimiento que estas razones provoquen en la persona, la naturaleza atroz del suicidio no desaparezca, pues, como sostiene Pedro de Aragón, provocarse la propia muerte supera cualquiera de las miserias que el hombre pueda soportar en su vida ${ }^{4}$. Desde luego, la práctica jurídica exige con rigor teórico que, si la parte acusada pretende demostrar que el suicidio se produjo por tedio vital o dolor, deba probarlo, contra la presunción de dolo; la dificultad probatoria es mayor que en el suicidio por conciencia del crimen o el miedo a la pena, pues en éste las circunstancias objetivas de otro crimen cometido, de la persecución o prendimiento o procesamiento judicial (a partir de la litispendencia o de un momento procesal anterior) activan la modalidad de suicidio automáticamente. Pues bien, en las alegaciones de la defensa en nuestro caso se argumenta precisamente que Juan López de Uceda anduvo falto de juicio días antes del suceso, negando por tanto que se tratara de un suicidio doloso o premeditado ${ }^{5}$. Se dice así ante la justicia local:

«[...] e porque caso negado que el susodicho [refiriéndose a Juan López de Uceda] se hubiera ahorcado, sería estando fuera de juicio como en realidad de verdad lo estaba e sin memoria de algunos días antes; e al tiempo que decían le habían hallado muerto porque hacía muchas locuras e disparates o no respondía a propósito como hombre desatinado e furioso como siendo necesario se averiguara en la prosecución de la causa e porque el dicho Juan López no había incurrido en perdimiento de bienes ni de parte de ellos y en caso necesario pedía al dicho alcalde mayor así lo declarase por las cuales razones e por las demás que habían en su favor $[\ldots]\rangle^{6}$.

Aragón, De iustitia et iure, cit., pp. 356-357, 361.

Recientemente, sobre la relación entre demencia y suicidio, vid. Elena del Río Parra, «Vivir en el extremo. Locura y suicidio en la temprana modernidad española», e-Humanista, 36 (2017), pp. 1-22.

6 «Ejecutoria», cit., fol. 12. 
Y se insiste en esta razón, incluso haciendo un mayor hincapié en el estado de furor y locura que padecía Juan López antes de su muerte, ante la justicia superior de la Real Chancillería de Valladolid:

«[...] la dicha sentencia la cual era ninguna injusta e de revocar por lo siguiente: lo primero por lo general y lo demás que en su favor resultaba del proceso e porque negaba el dicho Juan López haberse ahorcado a sí mismo y por derecho e no se podía presumir ni estaba contra él probado que cuando se ahorca Juan López antes y al tiempo que había parecido muerto estaba loco y furioso y fuera de su juicio natural y como tal de veinte días que decía y hacía cosas e porque últimamente había mostrado estar fuera de su juicio y más siendo como era y había sido el dicho Juan López todo el discurso de la vida hombre muy entendido y discreto y por lo cual conocido e tenido en la dicha villa de Talavera $[\ldots]^{7} \gg$.

Este argumento es interesante porque profundiza en la incapacidad de dolo, y señala como su causa la falta de juicio y el estado de locura mental que padecía el reo días antes de su ahorcamiento. De manera que, aunque parece que a la defensa le interesa probar que el tipo de suicidio que practica Juan López está ligado al tedio vital, para derivar su incapacidad, lo cierto es que no utiliza conceptos evanescentes o difíciles de precisar en magnitud como el propio tedio, o el dolor, sino que opta por hacer operativa como causa de este tipo de suicidio el furor, la locura, la demencia. Este cambio conceptual no es asunto baladí si se tiene en cuenta que precisamente la demencia y la enajenación mental constituían causas reconocidas por la doctrina jurídica unánimemente para fundamentar la incapacidad de dolo del acusado, y por consiguiente constituían un criterio técnico consolidado para la exención de la pena o, en su defecto, la imposición de una pena arbitraria extraordinaria. En líneas generales, la literatura jurídica moderna explica que el loco, al carecer de juicio o intelecto, sufre una enajenación mental, de tal manera que cualquier acto que lleve a cabo carece de dolo e inteligencia. A tal efecto la jurisprudencia moderna traza una tipología de la locura, diferenciando la continuada de la sobrevenida, valorando a su vez los supuestos ocasionales de lucidez por los que pueda el enajenado atravesar en el momento de la comisión del crimen. En este sentido, Antonio Gómez entiende que, habida cuenta de que en todo delito rige la presunción iuris tantum de dolo, la carga de la prueba de la demencia corresponderá a la parte acusada, mientras que la parte acusadora, si la demencia ha sido probada, cargará con la prueba de que la comisión del crimen se efectuó durante un intervalo de lucidez; el origen del furor es una enfermedad que, de ser confirmada por los médicos peritos, se presume continua y perdurable en el tiempo, pero esta consistencia es ulterior y no se contradice con que la parte afectada tenga obligación de demostrar que concretamente, en el preciso momento de la comisión del crimen, el reo actuaba falto de juicio, sumido en la enajenación mental ${ }^{8}$. Con un tono parecido, Julio Claro y Joos Damhouder defienden el criterio asentado según el cual, de confirmarse la locura, rige la incapacidad de dolo y la exención de pena: la justicia no debe castigar al delincuente que cometió el delito durante un intervalo de furor pues la locura se considera tortura y condena de por

Ibid., fols. 29-30.

Antonio Gómez, Variae resolutiones juris civilis, communis, et regii, tomis tribus distinctae, Tomus tertius, Matriti, Typis Petri Marin, 1780, pp. 42-43. 
sí suficiente, a lo que se une la imposibilidad de que quien no es dueño de su mente pueda hacer nada con ánimo deliberado ${ }^{9}$. Este efecto de la demencia es tan reconocido jurídicamente que afecta no sólo a la valoración de la participación en el crimen, sino también a la ejecución de la pena; asegura Claro como de opinión común, apoyándose en Baldo, que debe suspenderse la ejecución de la pena corporal sobre quien cometió un delito estando en su sano juicio, sin antecedentes de inestabilidad mental, cuando la locura sobreviene una vez dictada la sentencia condenatoria antes de la ejecución del castigo; algunos juristas se decantan por defender la imposición de una pena arbitraria mitigada, pero ninguno a favor de la pena ordinaria ${ }^{10}$. Como razona Diego de Covarrubias, la aplicación de la pena en situación de locura sería defectuoso porque el reo no sería plenamente consciente de su condena, y la ejecución en sí no resultaría en rigor equiparable a la imposición de un castigo; esto no significa, con la misma lógica de necesidad probatoria que comentábamos antes, que no deba plantearse la posibilidad de que la locura sea fingida por parte del reo, precisamente con el fin de evitar la condena, lo que habrá de resolverse mediante la presentación de pruebas que demuestren el furor, en el caso de la parte acusada, o la lucidez, en el caso de la parte acusadora ${ }^{11}$. Sin embargo, el régimen suspensivo de penas corporales parece no regir respecto de las penas patrimoniales, que en definitiva se deben aplicar aun devenida la demencia del reo tras el fallo judicial, como advierte Claro ${ }^{12}$.

Si nos ceñimos a nuestro pleito, es evidente que las alegaciones de la defensa se aproximan más a la teoría jurídica de la demencia como causa de incapacidad de dolo que a otros fundamentos o motivaciones del suicidio relacionados con el tedio vital, quizá más complejos de probar dada su vaguedad significativa, corriendo el riesgo la defensa de construir unos alegatos confusos y ambiguos. Este desplazamiento del suicidio hacia la demencia parece además evidente en la forma como la defensa hace hincapié en la continuidad de la locura, desde un tiempo anterior, con el intento de pasar a la acusación la carga de la prueba de un intervalo lúcido; el hecho de que el suicidio no obedezca a una enajenación mental momentánea, ni a su interrupción, aboga a favor de la exención punitiva absolutoria. Este régimen solo la demencia lo permite, pero no otras formas aun próximas como la ira, y por lo tanto tampoco el dolor ni el tedio; no puede ser casualidad, en conclusión, la sustitución de conceptos.

\subsection{De la conciencia del crimen o miedo a la pena a la conciencia o miedo de la responsabilidad civil}

Un supuesto que plantea problemas relevantes para la literatura jurídica moderna es el suicidio cometido por razón de la responsabilidad derivada de un acto criminal consumado previamente por el propio suicida, lo cual resulta contemplado desde dos posibles situaciones temporales: por un lado, la consciencia criminis, anterior a

Julio Claro, Opera Omnia, sive practica civilis atque criminalis, Lugduni, Sumpt. Horatii Boissat, \& Georgii Remeus, 1661, p. 654; Joost Damhouder, Praxis rerum criminalium, elegantissimis iconibus ad materiam accommodis illustrata, praetoribus, propraetoribus, consulibus, proconsulibus, magistratibus, reliquisque id genus Iustitiariis ac Officiariis, aprimè utilis ac necessaria, Antuerpiae, Apud Ioannem Bellerum, sub insigni Falconis, 1555, pp. 284-285.

10 Julio Claro, Opera Omnia, cit, p. 655.

11 Diego de Covarrubias, Opera omnia, Genevae, Sumptibus Cramer, Perachon \& Cramer Filii, 1724, p. 706.

12 Julio Claro, Opera Omnia, cit., p. 655. 
la detención del criminal por la justicia, y por otro lado el metus poenae, al que da lugar la conciencia del crimen cuando el criminal ha sido ya detenido o cuando ha comenzado el proceso que enjuicia su eventual culpabilidad. El hecho de que este tipo de suicidio tenga una especial importancia jurídica, y active el merecimiento de pena por el propio suicidio, responde a la protección de la eficacia de la justicia pública, ya que el suicidio del criminal evitaría la pena, y, por consiguiente, mermaría la eficacia de los aparatos represivos de la administración de justicia secular y eclesiástica. Técnicamente, el suicidio opera como la comprobación de la culpabilidad por el delito anterior, a modo de cosa juzgada en el caso de que todavía no se hubiera pronunciado sentencia, o convicto y confeso el reo en calidad de prueba plena $^{13}$. Esto explica el mayor rigor aplicado al suicidio por conciencia de crimen o miedo a la pena, pues a la presunción de culpabilidad se unen otros efectos, como el impedimento a los herederos del suicida de ejercer acciones procesales en orden a la prueba de la inocencia del reo, aunque a veces se matiza el criterio dependiendo del momento procesal en el que se encontrara el suicida: la presunción del miedo a la pena funciona, en el caso más laxo, tras la formulación de la acusación y la apertura del juicio plenario, y nunca antes de la captura del reo ${ }^{14}$.

En el pleito por el supuesto suicidio de Juan López de Uceda, la idea de un suicidio cometido por conciencia no de un crimen, sino de la responsabilidad civil derivada de una acumulación de deudas, o del miedo a una pena ya no en respuesta a un acto criminal, sino a las obligaciones y deudas asumidas, a las que parece no podía hacer frente el acusado, tendría que ser favorable a la acusación, aunque resulta muy difícil precisar si la responsabilidad civil alcanza tal volumen de deuda, o implica la realización de actividades fraudulentas o torticeras, hasta el punto de ser susceptible de transformarse, al menos en la mente del deudor suicida, en la posibilidad de una responsabilidad penal patrimonial. Ahora bien, hay que señalar que, como esta responsabilidad civil no se traduce directamente en una responsabilidad criminal, la interpretación literal de la institución permite también, frente a la equiparación o conexión de responsabilidades, sencillamente excluir un suicidio por conciencia de crimen o miedo de la pena, sobre todo por un motivo fundamental: el suicidio por esta causa se presume cuando se ha producido al menos la detención judicial del criminal, si no el comienzo del proceso, si no la litispendencia. Si no se ha llegado a este punto, la responsabilidad civil puede quedar reducida tan solo, para la acusación, a un dato que convence de la deliberación o premeditación del suicidio, pues constituye la causa que explica el comportamiento criminal. Así, el fiscal refleja en su acusación ante la justicia local de Talavera de la Reina y ante la Real Chancillería de Valladolid, que el suicidio de Juan López obedece a un acto plenamente deliberado precisamente por la precaria situación económica que atravesaba (en la que se apunta el orden de una suspensión de pagos) y el temor a posibles represalias resultantes del impago de sus deudas:

«[...] e por una petición de acusación que el dicho Gaspar Íñigo [promotor fiscal] ante el dicho alcalde mayor presentó, dijo que acusaba criminalmente a Juan

13 Así, en Pedro de Plaza y Moraza, Epitome delictorum, causarumque criminalium, ex iure pontificio regio \& caesareo. Liber I, Venetiis, apud Hieronymum Scotum, 1573, pp. 394-395, 407, y en Ziletti, Consiliorum, cit., f. 45 v.; el mismo régimen sería aplicable en el conato, como explica también Plaza y Moraza, Ibid, pp. 409-410, o Gómez, Variae resolutiones, cit., pp. 105-106.

14 Diego de Cantera, Quaestiones criminales tangentes iudicem, accusatorem, reum, probationem, punitionemque delictorum, Salmanticae, excudebat Cornelius Bonardus, 1589, pp. 555-557. 
López de Uceda, difunto, e premisas las solemnidades del difunto decía que era que el susodicho pospuesto el temor de Dios nuestro Señor y en gravísimo daño de su conciencia e alma habiendo algunos días imaginado el orden que podía tener para pagar sus deudas e para cumplir sus obligaciones que tenía cerca de la mayordomía de Juan Duque de Estrada e no pareciéndole que tenía remedio para ello, olvidando de Dios nuestro Señor e desamparado de su poderosa mano había determinado ahorcarse y él mismo dar muerte para concluir con todo [...] e visto por el dicho alcalde mayor e por todos los vecinos de la dicha villa con dolor grande y espanto de cuantos le miraban de ver un hecho tan atroz del demonio $\left.[\ldots]^{15}\right\rangle$.

El fiscal reitera el argumento ante la Real Chancillería de Valladolid, tras el recurso de apelación presentado por Diego López de Uceda:

«[...] estaba probado con muchos testigos e otras pruebas concluyentes el haber el dicho Juan López de Uceda, hijo del dicho Diego López, ahorcado desesperado de la misericordia de Dios e siendo así la sentencia contra él dada por ser conforme a las leyes de estos reinos era justa e se debía confirmar porque lo que el dicho pleito constaba e parecía era haberse el dicho Juan López ahorcado e que la causa había sido desesperado en Dios, e no creyendo verse harto de dineros e que por se hallar falto de ellos e quedar obligado a hacer e cumplir muchas $\cos a s[\ldots]\rangle^{16}$.

Efectivamente, cabe entender que Juan López de Uceda se mató a sí mismo desesperado por la ingente cantidad de deudas acumuladas, como expresa el fiscal. Es presumible que Juan López estuviera siendo presionado por sus acreedores, y en definitiva a la espera de una inminente intervención de la justicia para hacerle responsable del impago de sus deudas en un proceso que podría desembocar probablemente en una sentencia condenatoria de prisión en servidumbre como deudor insolvente; como explica Tomás y Valiente, el deudor estaría obligado a ceder sus bienes, de manera que, si éstos fueran insuficientes para hacer frente a todas sus deudas, permanecería en prisión preventiva hasta la total cesión patrimonial, y en su defecto sería entregado en servidumbre de manera sucesiva a sus acreedores ${ }^{17}$. Sin embargo, objetivamente no se había producido ninguna diligencia judicial en contra del futuro suicida. Lo que sí está ya presente es un temor, que podría serle útil a la defensa para explicar la perturbación mental que experimentó el sujeto: si no la conciencia de un crimen (siempre diferenciable de una obligación civil), el miedo a la pena (que aproxima las obligaciones civil y criminal como respuesta a su incumplimiento), en un tiempo anterior y acaso próximo a la debacle, puede provocar su alteración psicológica. Pero en definitiva, tanto en el hipotético servicio a la versión de la acusación como en el de la defensa, la responsabilidad civil parece ser una circunstancia fáctica que no condiciona el suicidio ni como justificación ni como forma de presunción de su causa.

\footnotetext{
«Ejecutoria», cit., fols. 12-13.

Ibid., fols. 30-31.

Sobre la prisión por deudas vid. Francisco Tomás y Valiente, «La prisión por deudas en los Derechos castellanos y aragonés», Anuario de Historia del Derecho Español, 30 (1960), pp. 375-435.
} 


\section{Problemas judiciales en las penas del suicidio}

\subsection{Práctica de la sepultura}

Por lo general, el suicida queda excluido de la comunidad religiosa por el pecado mortal cometido, dado que su desesperación ha provocado no sólo la destrucción del cuerpo, sino también del alma, de modo que la esperanza del perdón divino es absurda e inútil, e imposible la esperanza en la salvación eterna; por lo tanto, las costumbres de los ritos, lutos y llantos por el alma del suicida se vuelven absurdas $\mathrm{y}$, si hubieran de ser admitidas, habría de ser mínimamente, más por la piedad de quien los realiza que por el alma misma del suicida ${ }^{18}$. De esta forma, al suicida le es denegada la sepultura eclesiástica, no siendo enterrado en sagrado; será la costumbre territorial la que marque el destino del cadáver: como recuerda Alfonso de Acevedo, una práctica castellana fue la de arrojar el cadáver al río ${ }^{19}$. En este sentido, aunque el Derecho civil conceda relevancia a la distinción de dos tipos de suicidios, por conciencia criminal o miedo de la pena, y por tedio vital y causas similares, a los ojos de la Iglesia el suicidio es siempre igual de pecaminoso ${ }^{20}$, lo que no excluye que, antes de la denegación de la sepultura eclesiástica, la Iglesia tenga que inquirir las circunstancias en las que el sujeto se quitó la vida, para la prueba de la deliberación del suicidio, la exclusión de la intervención de tercero o la constatación de una causa de discapacidad mental ${ }^{21}$.

Si la determinación o denegación del enterramiento en sagrado del cadáver del presunto suicida responde a un proceso inquisitivo dependiente de la justicia eclesiástica paralelo al proceso judicial abierto por la justicia secular para la averiguación del homicidio cualificado, en el pleito que estamos analizando la práctica llevada a cabo para proceder al enterramiento de Juan López de Uceda parece estar manifestando una descoordinación entre ambas jurisdicciones.

En un primer momento parece que únicamente la jurisdicción ordinaria se ha encargado de ordenar qué hacer con el cadáver: el alcalde mayor ordena que sea enterrado en un hoyo a las afueras, en la otra parte del río Tajo. A simple vista, dado que la orden de traslado y enterramiento del cadáver se produce en el momento inicial del proceso judicial, concretamente durante la información sumaria, podría suponerse que se trata de una medida de salud pública; en ningún momento la autoridad local menciona la participación de la autoridad eclesiástica en el traslado y enterramiento del cadáver, como si se quisiera soslayar o absorber sus competencias:

«[...] el dicho alcalde mayor mandó enterrar el cuerpo del dicho Juan López de Uceda en uno hoyo de la otra parte del río Tajo entre tanto que se averiguase la verdad e recibió más información de lo susodicho, e dispuesto por mandado del dicho alcalde mayor, se mudó el cuerpo del susodicho a otra parte $[\ldots] \aleph^{22}$.

\footnotetext{
18 Es opinión común, así por ejemplo en Iacobus de Bello Visu, Avrea practica criminalis, cit., p. 591; o en Damhouder, Praxis Rerum, cit., pp. 310-314.

19 Alfonso de Azevedo, Commentarii juris civilis in Hispaniae regias constitutiones. Tomus quintus octavum librum novae recopilationis complectens, Lugduni, apud fratres Deville, 1737, p. 446.

20 Gómez de Amescua, Tractatus, cit., p. 188.

${ }^{21}$ Ibid., pp. 186-189.

22 «Ejecutoria», cit., fol. 10.
} 
No obstante, el promotor fiscal explica que la denegación de la sepultura eclesiástica se produce en cumplimento de una decisión adoptada por el alcalde mayor de Talavera de la Reina que, a partir de una cierta valoración de las circunstancias, presume con seguridad que se trata de un crimen de suicidio y ordena el entierro profano del cuerpo basado en la evidencia del crimen:

«[...] se había ahogado e ahorcado él mismo quedando ahorcado e muerto naturalmente según había sido hallado e visto por el dicho alcalde mayor e por todos los vecinos de la dicha villa con dolor grande y espanto de cuantos le miraban de ver un hecho tan atroz del demonio, por lo cual había sido mandado depositar y enterrar al campo donde al presente estaban y en lo así haber hizo fuerza de lo haber incurrido en perdimiento del alma y en otras penas había incurrido en perdimiento de sus bienes por leyes e pragmáticas de estos reinos $[\ldots]\rangle^{23}$.

Parece notorio que Juan López optó por privarse de la vida ahorcándose, según lo entiende el alcalde mayor en su inspección ocular, en el momento del levantamiento del cadáver, así como los vecinos que presencian con gran escándalo el cuerpo ahogado. La notoriedad facti ha sido determinante, añadida a la atrocidad del crimen, y quizá la razón por la que han podido sortearse otras irregularidades. En primer lugar, la autoridad competente para decretar la denegación de la sepultura debería ser la eclesiástica, pues así lo estipula el Derecho canónico, de manera que la justicia secular avoca competencia ajena. En segundo lugar, la jurisdicción local obvia, al adelantar la imposición de la pena, una inquisición judicial que permita valorar las cualidades del hecho delictivo junto con los signos e indicios que se hallen en él e influyan en la consideración de la voluntariedad del acto para determinar si el suicidio de Juan López obedece a un acto deliberado y premeditado. De alguna forma, dada la atrocidad del delito, parece aplicarse la sumariedad al menos en lo que concierne a la disposición del cuerpo, prescindiendo de las pesquisas necesarias; y ello a su vez deriva en el incumplimiento de la posibilidad de prueba en contrario de la presunción iuris tantum, al entender que Juan López es culpable de un crimen de suicidio y decidir de inmediato el enterramiento de su cuerpo fuera de recinto sagrado.

En un segundo momento, el contenido del pleito constata el hecho de que en su transcurso la jurisdicción eclesiástica se ha desenvuelto paralelamente a la local haciendo valer su disposición sobre el cadáver de Juan López de manera jurídicamente satisfactoria, tras haber asumido la investigación previa correspondiente para determinar el enterramiento del cuerpo:

«[...] e porque por lo susodicho así el juez eclesiástico que había conocido en la dicha razón sobre dar eclesiástica sepultura al cuerpo del dicho Juan López por su sentencia le había mandado dar y se la había dado [...] y asimismo se mostro cierta sentencia por el licenciado Miguel González vicario general de la dicha villa dada en que manda enterrar el cuerpo del dicho Juan López de Uceda en lugar sagrado e cierta información recibida como se había enterrado en cumplimiento de la dicha sentencia el dicho cuerpo e huesos del dicho Juan López de Uceda en lugar sagrado $[\ldots]\rangle^{24}$. 
Cabe pensar que la intervención de la justicia eclesiástica está condicionando a la justicia secular, si bien se trataría de una interferencia de hecho, no de un formal conflicto de jurisdicciones, pues procesalmente no obliga a la justicia local a declinar su competencia y abandonar el proceso. La sustanciación de un proceso por la jurisdicción eclesiástica afecta a la decisión secular en lo referente a su medida temprana de enterramiento del cadáver, y pone en entredicho la capacidad de actuación de la autoridad local, ya que en contraposición el vicario general de la villa de Talavera de la Reina se pronuncia finalmente a favor de enterrar el cadáver en sagrado, provocando la ineficacia del auto o sentencia de la autoridad local. De este modo, el cuerpo de Juan López es exhumado y trasladado al cementerio, en cumplimiento de la sentencia dictada por el vicario general. La perturbación en el caso que aquí tiene lugar responde a que la sentencia del vicario ha tenido que derivar de la apreciación de la ausencia de pruebas palmarias que demostrasen que Juan López se ahorcó, o que lo hizo con verdadero dolo, y por consiguiente cuestiona la notoriedad del hecho que por el contrario sí contemplaba la jurisdicción secular.

\subsection{Práctica de la confiscación de bienes}

Ordinariamente, la administración de justicia impone al suicida la misma pena que al homicida: excluida por la costumbre la pena simbólica del ahorcamiento del cadáver, se ordena la confiscación de bienes. No obstante, la legislación castellana, con el apoyo de la doctrina jurídica, limita la pena al suicidio por causa de conciencia de crimen o miedo de la pena, y la excluye del suicidio por causa de tedio vital, impaciencia o dolor (Partidas 7.27.2 y Nueva Recopilación 8.23.8). Próspero Farinacio, que dedica una extensa parte de su obra al análisis de la pena de confiscación de los bienes como condena del suicida, sostiene así su aplicación al suicidio cuya causa es la conciencia del crimen o el miedo de la pena, causa presumida una vez abierto un procedimiento judicial, conforme a la opinión común de los doctores que aboga por la excepcionalidad de la pena de confiscación, retraída en el supuesto de que los herederos del suicida probaran que el crimen fue causado por el tedio vita ${ }^{25}$.

En nuestro pleito, no existe un crimen anterior ni un proceso criminal abierto contra Juan López de Uceda que permita presuponer un suicidio por conciencia de crimen o miedo a la pena; sin embargo, aun a falta de este presupuesto legal, el fiscal pide la confiscación de sus bienes en cuanto pena legal ordinaria estipulada por el Derecho castellano. La acusación arguye la evidencia de un suicidio provocado por una situación desesperante provocada por la insolvencia financiera del acusado, pero no había detención ni prisión ni proceso civil ni criminal abierto, y la probable responsabilidad civil, o penal patrimonial en caso de mayor gravedad, como vimos anteriormente, no parece haberse entendido como equivalente a la conciencia de crimen (sino como prueba de la deliberación en el suicidio), al menos de forma expresa (ahora resulta dudoso si de forma tácita).

El alcalde mayor, que ordena como medida cautelar el embargo de los bienes del sujeto para proseguir con la investigación, asume la argumentación del fiscal:

Farinacio, Praxis, cit., pp. 323-329. 
«[...] respondiendo a una querella e acusación dada por Gaspar Íñigo promotor criado por la justicia en que decía haberse ahorcado el dicho Juan López de Uceda, e por ello había incurrido en perdimiento de todos sus bienes e que se adjudicasen a la cámara del cardenal arzobispo de Toledo según se contenía en su acusación su señor en lo necesario habido por respetado $[\ldots] \aleph^{26}$.

«[...] y en lo así haber hizo fuerza de lo haber incurrido en perdimiento del alma y en otras penas había incurrido en perdimiento de sus bienes por leyes e pragmáticas de estos reinos; por lo cual pudo el dicho alcalde mayor que ante todas cosas declarase el dicho Juan López de Uceda haberse ahorcado a sí mismo voluntariamente e lo condenase a él e a cualquiera persona que pretendiese derecho a sus bienes en perdimiento de ellos aplicándolos e adjudicándolos a la cámara del dicho cardenal de la dicha villa sin que de ellos faltase cosa alguna e sobretodo pedía justicia e costas e juraba en forma la dicha acusación; otrosí dijo que pedía al dicho alcalde mayor secuestrase y embargase todos e cualesquier bienes que pareciesen ser de Juan López de Uceda e que todos se pusiesen en poder de una persona que los tuviese de manifiesto de la cual dicha petición por el dicho alcalde mayor fue mandado dar traslado a la otra parte y en prosecución de las dichas diligencias e averiguaciones se hizo el embargo del tenor siguiente $[\ldots] \gg{ }^{27}$.

Finalmente, la justicia local dicta sentencia condenatoria por homicidio cualificado, entendiendo que las alegaciones presentadas por la acusación son suficientes y que, consiguientemente, la premeditación y deliberación del acto evidencian la naturaleza atroz del crimen, privando de sus bienes como justa condena a los herederos de Juan López:

«[...] por el dicho delito sirve en él haberse quedado confiscados y portados los bienes confiscados, lo declaró y aplicó a la cámara e fisco como por la ley se aplica $[\ldots] \gg{ }^{28}$.

La parte acusada interpone recurso de apelación contra la sentencia del alcalde mayor ante la Real Chancillería de Valladolid. Precisamente, la defensa hace hincapié en la dureza de una condena que, en contraposición con la ley y la doctrina jurídica mayoritaria, incumple con el criterio general de ser aplicable en supuestos limitados y bien probados, como por lo común sería la existencia de un delito anterior y el miedo a la pena, ambas situaciones obviamente insertas en un proceso criminal abierto. La defensa se expresa considerando la disconformidad de la sentencia con la ley y el Derecho, aunque se echa de menos que insista en la condición procesal propia de la única causa de suicidio que aparejaba legalmente confiscación, quizá porque el fiscal había tomado la precaución, por mucho que en él hiciera mella ocultamente la equiparación de responsabilidad civil y penal, de no referirse a un requisito legal que sabía no resultaba cumplido en este caso concreto. Así, la defensa considera solamente que la aplicación de la confiscación constituye una imposición arbitraria de la pena, poniendo de relieve que no se ha respetado la excepcionalidad característica de una pena mayor, en este supuesto desproporcionada y que no guarda respeto hacia la

«Ejecutoria», cit., fol. 11.

Ibid., fol. 13 .

Ibid., fols. 28-29. 
regular preservación de las expectativas hereditarias de los sucesores legítimos que establecía la ley en el concreto crimen de suicidio (de la que se había desentendido la sentencia de primera instancia, quizá porque la ley recopilada literalmente respetaba los intereses de los «herederos descendientes», no de los ascendientes):

«[...] porque cuando lo susodicho cesara que no cesaba que no era aquel caso tal porque por el conforme a derechos e leyes de los nuestros reinos se incurría en confiscación e perdimiento de bienes mayormente en perjuicio de los herederos legítimos que había dejado el dicho Juan López los cuales habían sido los dichos sus padres en nombre de su parte e por lo cual nos pidió e suplicó mandásemos revocar e revocásemos la dicha sentencia $[\ldots] \gg{ }^{29}$.

La acusación se limitó a defender los términos de la sentencia local, constatando que el embargo se producía sobre los bienes propios de un sujeto emancipado sui iuris, quizá con el objeto de garantizar la aplicación de una confiscación con riesgo de ser complicada por la extrema condición deudora de Juan López, tratando de sortear el probable requerimiento de terceros:

«[...] e porque los bienes que al dicho Juan López ahorcado se le habían secuestrado habían sido y eran suyos propios e como tales los poseía e gozaba e tenía por suyos propios e se los había dado su padre y era emancipado como hombre sui iuris los tenía e poseía administraba e gozaba, vendía y locaba y cambiaba $[\ldots] »^{30}$.

Cuando la sentencia de vista absuelva al supuesto suicida, quedará la duda de saber si en el tribunal ha pesado esa ausencia de procedimiento judicial abierto que habría excitado la causa de miedo a la pena por deudas que tanto parecía poder haber temido el fallecido reo, pero el respeto legal a los derechos hereditarios en un sentido amplio, que limita la aplicación de la confiscación de bienes explícitamente en el suicidio, ha podido ser otro factor influyente.

\section{La prueba del suicidio}

\section{Prueba de la cualificación del crimen}

El suicidio está contemplado por la doctrina jurídica como un crimen de homicidio cualificado, en el que se presume iuris tantum el dolo pero en el que la carga de la prueba respecto de la cualificación recae sobre la acusación. Ahora bien, el hecho de que en el suicidio la cualificación resida en la confusión entre criminal y víctima impide, como explicamos anteriormente, que exista una figura simple de este crimen cualificado, de modo que dolo simple y premeditación cualificada tienden también a confundirse. Lo que cabe plantear es si esta confusión funciona a favor de la suficiencia de la presunción de dolo o de la necesidad de prueba de la cualificación, con mayor razón cuando en el suicidio el dolo ha tenido que ser forzosamente premeditado. 
En nuestro pleito, cuando Juan López de Uceda es hallado muerto por ahorcamiento, a pesar de que las diligencias judiciales del alcalde mayor van a ser rápidas a partir de una presunción de suicidio que parece clara, se razona en el sentido de que el suicidio debe ser probado, contra la mera apariencia, de manera que la falta de prueba no derivaría en dolo simple, sino en ausencia de dolo y por lo tanto de crimen:

«[...] e no constando como no constaba que él mismo se ahorcase ni testigo que le viese ahorcar la presunción del dicho estaba en su favor e porque a ello no impedía el haber sido hallado con una soga al cuello porque aquello no era probanza conveniente $[\ldots] \gg\rangle^{31}$.

No hay testigos directos del ahorcamiento. Incluso, en un momento de la contestación a la acusación formal ante la justicia local, la defensa siembra sospechas sobre la posibilidad de que se trate de un homicidio:

«[...] pues había podido ser que otro le ahorcase mayormente teniendo como tenía

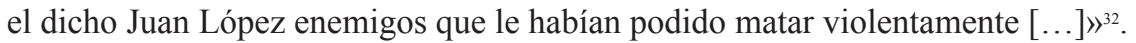

Precisamente contra esas sospechas, que trasladan al homicidio la presunción de dolo simple, corresponderá a la acusación probar la realidad del suicidio, lo que coincide con la necesidad de prueba de la cualificación. En definitiva, el promotor fiscal tendrá que demostrar con claridad la existencia de un suicidio que obedezca a un acto voluntario y precisamente será esa voluntariedad -más compleja de determinar por su intrínseca premeditación y por la confusión de criminal y víctima- la que constituya el agravante del homicidio.

\section{Circunstancias probatorias}

\subsection{Modo de la muerte}

Como se detalla en la ejecutoria, Juan López de Uceda apareció ahorcado a ras de suelo sobre una ventana baja de una de las casas de Diego Alonso, vecino también de la villa de Talavera de la Reina. La extraña muerte por ahorcamiento del sujeto da lugar a la apertura de una investigación judicial, con inspección ocular, que permita recopilar cualquier información útil para la averiguación de los hechos:

«[...] sobre razón que parece que en la dicha villa de Talavera a treinta días del mes de agosto de mil e quinientos e ochenta e nueve años, Pedro de Villacorta, alcalde mayor de la dicha villa e su tierra habiendo sido informado que Juan López de Uceda, vecino de la dicha villa estaba ahorcado e muerto naturalmente e para averiguar la verdad fue a las casas de Diego Alonso, vecino de la dicha villa de Talavera que eran por bajo de las carnicerías de ella donde se informó estaba ahorcado el dicho Juan López e así entró en las dichas casas y en ellas halló al dicho Juan López de Uceda ahorcado de una ventanilla de reja baja con una soga a la 
garganta asida a la dicha ventanilla el dicho Juan López sentado en el suelo sobre cual dijo hacía cabeza de proceso para averiguar la verdad de lo susodicho $[\ldots]\rangle^{33}$.

En consecuencia, el fiscal acusa criminalmente a Juan López de Uceda por un crimen de suicidio, adoptando como principal alegato su condición de deudor insolvente y su temor al deber de hacer frente a un proceso judicial como responsable por incumplimiento de sus obligaciones civiles:

«[...] e por una petición de acusación que el dicho Gaspar Íñigo ante el dicho alcalde mayor presentó dijo que acusaba criminalmente a Juan López de Uceda, difunto, premisas las solemnidades del dicho decía que era que el susodicho pospuesto el temor de Dios Nuestro Señor y en gravísimo daño de su conciencia e alma habiendo algunos días imaginado el orden que podrá tener para pagar sus deudas e para cumplir sus obligaciones que tenía cerca de la mayordomía de Juan Duque de Estrada, e no pareciéndole que tenía remedio para ello, olvidando de Dios Nuestro Señor e desamparado de su poderosa mano había determinado ahorcarse y el mismo dar la muerte para concluir con todo [...] e obstinado y endurecido el susodicho se había ido a una ventana baja de reja de la dicha casa e doblándola otra soga nueva que allí tenía la había metido por entre la reja de la dicha ventana e se la había puesto al pescuezo la cual había apretado él mismo con sus propias manos, tanto que sentado en el suelo por no poner su negocio en ventura se había ahogado e ahorcado él mismo quedando ahorcado e muerto naturalmente $[\ldots]^{34}$.

Empero, hay una circunstancia clave en la investigación que parece ser soslayada en la acusación, y es la extraña posición en la que resulta hallado el cuerpo, aunque algo llama la atención al fiscal cuando sostiene, en relación con un conato de suicidio anterior por parte del mismo sujeto (que comentaremos más adelante) cómo, tras fracasar en su primer intento, Juan López habría decidido doblar una segunda cuerda entre la reja de la ventana y, rodeando su cuello con la soga, se daría a sí mismo muerte tirando de ella con sus propias manos. Esta hipotética descripción de los hechos no parece encajar en una explicación de la evidencia del suicidio, de ahí que la defensa aproveche para exponer una explicación que obedezca a un homicidio cometido por un tercero:

«[...] e no constando como constaba que él mismo se ahorcase ni testigo que le viese ahorcar la presunción del dicho estaba en su favor e porque a ello no impedía el haber sido hallado con una soga al cuello porque aquello no era probanza conveniente pues había podido ser que otro le ahorcase mayormente teniendo como tenía el dicho Juan López enemigos que le habían podido matar violentamente e aquello se dejaba dar o entender porque el dicho Juan López había aparecido muerto al pie de una ventana muy baja sentado en el suelo, e la soga no tenía lazada, e los muslos tenía acardenalados a manera de que alguna persona había hecho fuerza sobre ellos, e apretándole las manos para matarle de suerte que parecía imposible haberse él mismo ahorcado ni jamás se había hallado ahorcado de aquella manera [...] $\rangle^{35}$.

Ibid., fol. 3 .

Ibid., fols. 12-13.

Ibid., fols. 11-12. 
La postura del fallecido es forzada: la evidencia del suicidio no es, pues, tan fuerte. La acusación pretende probar que la posición del cuerpo es plausible por la misma dificultad de la comisión del crimen. La defensa opone entonces la posibilidad de un homicidio a favor del cual incorpora en su argumentación la existencia de enemigos de Juan López, en referencia más que probable a sus acreedores. Esto es interesante, porque la parte acusada da un giro a la exposición de los hechos aprovechando una responsabilidad civil desbordada que la acusación había utilizado para sostener la deliberación, dolo o premeditación del suicidio. Son relevantes aquí los aspectos periciales de medicina legal: no sólo la posición del cuerpo, sino también los muslos acardenalados, o la posibilidad de apretar fuertemente las manos durante la asfixia. Así, podría concluirse que en las posiciones de querella y contestación, y también en la prueba del crimen, ha tenido que tener una importancia fundamental, tanto para la acusación como para la defensa, la comprobación del cuerpo del delito practicada en la información sumaria.

\subsection{Conato o continuidad en el acto de suicidio}

La doctrina jurídica considera que las disposiciones punitivas para con el homicidio cualificado, como es el suicidio, han de regir tamquam principalis en el conato o atentado, aunque haya de valorarse si éste consiste en actos próximos o remotos (se prefiere la imposición de la pena ordinaria para el conato consistente en actos próximos, y de la pena extraordinaria para el consistente en actos remotos). En nuestro caso la acusación trae a colación un posible conato de suicidio de Juan López de Uceda reflejado en la información sumaria y difícil de distinguir, por su inmediatez temporal respecto de la consumación, de un delito continuado de suicidio. Bien es cierto que, como el suicidio ha sido perfecto al segundo intento, esto impide cualquier sustanciación judicial independiente respecto del conato anterior. Se trata de una información muy minuciosa:

«[...] para el mismo efecto un día que se contaron treinta días del mes de agosto del dicho año había ido a las casas que decían de Diego Alonso que habrían en la calle de Santa Leocadia lindero de casas de Diego de Orozco en las cuales el susodicho había vivido el año pasado e cerrando la puerta principal de la dicha casa tras sí se había quedado en ella a solas con dos sogas gordas de esparto la una vieja e la otra nueva que para que el efecto había comprado y echando la soga vieja a una viga se la había atado el pescuezo e había permitido Nuestro Señor por entonces usar de Su Misericordia con él quebrándola aunque era gorda e fuerte $[\ldots] \gg^{36}$.

En esta tesitura, el fiscal utiliza la información como un argumento de refuerzo de la atrocidad del crimen de suicidio, al considerarlo una confirmación efectiva, fáctica y no meramente mental, de la premeditación. Además, la compra de una soga nueva, ante la posibilidad de quiebra de la vieja, es considerada también por el fiscal como una cualidad delictiva que demostraría la preparación del crimen. La contestación de la defensa es huidiza y escueta, y continúa en la hipótesis del homicidio:

\footnotetext{
Ibid., fols. 12-13.
} 
«[...] y el de los que había parecido haberse quebrado otra soga en las dichas casas, había podido ser astucia de las personas que se habían hallado en la dicha muerte para que se entendiese que el dicho Juan López lo había hecho [...] $\rangle^{37}$.

Por cierto que la defensa desaprovecha un argumento de peso a su favor, como es la circunstancia de que el cuerpo de Juan López sufriera tales fuerzas y haya sido hallado en una casa ajena en la que había vivido hasta un año antes del episodio, y no en la vivienda en la que actualmente residía.

\subsection{Persistencia temporal de la demencia.}

Como ya se ha explicado, la persistencia de un estado de locura que días antes del presunto suicidio se apoderó del sujeto constituye una circunstancia probatoria que la parte acusada aprovechará para excluir el dolo. Es un argumento que se plantea como subsidiario respecto de la hipótesis de que se hubiera cometido un homicidio:

«[...] e porque caso negado que el susodicho se hubiera ahorcado, sería estando fuera de juicio como en realidad de verdad lo estaba e sin memoria de algunos días antes $[\ldots]\rangle^{38}$.

Si la defensa sostiene que días antes del suicidio Juan López de Uceda anduvo falto de juicio y desmemoriado, es porque, aunque se trate de una repentina enajenación mental (pues se entiende que se trataba de un hombre lúcido e inteligente) ese comienzo anterior permite presumir la continuidad de la demencia, que no es así un estado sobrevenido de forma intermitente sino prolongada, que excluye salvo prueba en contrario un intervalo de lucidez.

En la tramitación del recurso de apelación, contra la sentencia local condenatoria ante la Real Chancillería de Valladolid, se invierte el valor de los argumentos de la defensa de modo que, desapareciendo la hipótesis del homicidio, se refuerza antes bien la idea de la enajenación mental del presunto suicida:

«[...] e porque negaba que el dicho Juan López haberse ahorcado a sí mismo y por derecho no se podía presumir ni estaba contra él probado y cuando se ahorcó el dicho Juan López antes y al tiempo que había aparecido muerto estaba loco y furioso y fuera de su juicio natural [...] a que de su parte decía y hacía cosas por las que claramente había mostrado estar fuera de su juicio $[\ldots]\rangle^{39}$.

No es complicado imaginar las dificultades que tiene fundamentar el argumento del homicidio, para el que no bastan los obstáculos suicidas en el modo de la muerte, por lo que la defensa se concentra en la razón o causa que ha encauzado una práctica secular de parcial despenalización del suicidio: el tedio vital, entendido, de una manera más efectiva, en su función de incapacidad, mediante la teoría de la demencia como incapacidad de dolo. De ahí la estrategia de insistir en su aparición anterior y en su persistencia en el tiempo: Juan López había perdido el juicio desde algunos 
días antes de su muerte, y ese tiempo de enfermedad «antes», ahora, al apelar, se explica como prolongado «al tiempo», subrayando que la demencia había estado presente con suficiente permanencia, esto es, de forma continua y sin intervalos de lucidez. Como la ley y la doctrina jurídica han reducido la imposición de la pena de confiscación de bienes al supuesto del suicida que, en litispendencia, se mata por conciencia del crimen o miedo de la pena, esta línea argumentativa promete la mayor facilidad que se deriva de la tendencia expansiva del tedio vital (presumido a falta del requisito legal de un procedimiento abierto) y reafirmado además por una causa clásica, como es la demencia, de inimputabilidad.

\subsection{Inventario de documentación obligacional}

Como se ha destacado varias veces a lo largo de estas páginas, el fiscal formula la acusación por un delito atroz de suicidio fundamentando la deliberación en la desesperación provocada en Juan López de Uceda por la acumulación de deudas. En la prosecución de las diligencias y averiguaciones necesarias, el juez local solicita el embargo e inventario de toda la documentación acumulada por el sujeto para determinar con certeza su condición deudora. De esta forma, el alcalde mayor de la villa de Talavera, junto con el alguacil mayor y el escribano, acuden a la vivienda que Juan López había arrendado a Juan Duque de Estrada, en la que actualmente habitaba para realizar el inventario documental, encontrándose una importante cantidad de documentos de diversa naturaleza: crediticios (libros, cuadernos y memoriales de cuentas y bienes muebles; cartas misivas, reconocimientos, peticiones, cédulas, letras y libranzas de pago; mandamientos de cobro, obligaciones, billetes, testamentos, poderes y fenecimientos de cuentas; escrituras de reconocimiento y redención de censos y arrendamientos) y procesales (querellas, notificaciones, provisiones y mandamientos citatorios, requisitorios y compulsorios, autos, testimonios y traslados de interrogatorios, sentencias y mandamientos ejecutorios $)^{40}$. La desesperación por la responsabilidad civil si no criminal por deudas parece justificada.

\subsection{Fama del reo.}

Ciertos datos utilizados por las partes en el proceso constituyen, más que argumentos sólidos, indicios o conjeturas de escaso valor probatorio que refuerzan los principales argumentos alegados. Por ejemplo, la defensa procura poner de relieve la buena fama y conducta honorable de Juan López de Uceda, para trazar un perfil psicológico del sujeto impropio de un suicida o que al menos sirva para precisar, suponiendo que optara por privarse de la vida, que no existió dolo que motivara su acto. En este sentido se habla muy particularmente de la condición católico-practicante del reo, llegando incluso a concretarse que la última vez que recibió el sacramento de la confesión y la comunión fue ocho días antes de ser hallado muerto. El ahorcamiento, con la vileza e infamia que atrae su ejecución, sería contradictorio en un sujeto con unas creencias y prácticas religiosas tan sólidas:

40 Ibid., fols. 13-28. 
«[...] e así mismo la negaba haberse ahorcado el dicho Juan López ni tal se podía presumir por ser como era fiel e católico cristiano e que acudía a las cosas del servicio de Dios nuestro señor e se confesaba e comulgaba como era obligado e algunas veces entre año y en especial a ocho días poco más o menos que se pareciese muerto $[\ldots]\rangle^{41}$.

Además, la defensa presenta a Juan López como un hombre conocido, culto, intelectual y discreto antes de caer en la locura:

«[...] a que de su parte decía y hacía cosas por las que claramente había mostrado estar fuera e sin juicio y más siendo como era y había sido el dicho Juan López todo el discurso de la vida hombre muy entendido y discreto y por lo cual conocido e tenido en la dicha villa de Talavera e su comarca $[\ldots] \gg^{42}$.

Con lo que se consiguen dos objetivos simultáneos: convencer de que el suicidio no es acto que resulte propio de este carácter, y convencer de que la demencia en la que cayó un sujeto tan discreto no podía ser fingida. La buena fama y reputación social de Juan López parece estar respaldada con notoriedad por la totalidad de la comunidad de la villa y comarca de Talavera.

\subsection{Tipo de sepultura}

Recordemos brevemente cómo la jurisdicción eclesiástica había decidido el entierro en sagrado de Juan López de Uceda, de modo que, en cumplimiento de esta sentencia, el cadáver, que por decisión del alcalde mayor había sido enterrado a las afueras, fue exhumado y trasladado al cementerio. La decisión adoptada por la jurisdicción eclesiástica no afecta al proceso criminal abierto sobre el presunto suicidio de Juan López, que continúa su curso ordinario; empero, es utilizada por la defensa como una circunstancia probatoria en el recurso de apelación interpuesto ante la Real Chancillería de Valladolid. En efecto, la defensa alega que la sepultura eclesiástica presume un enjuiciamiento que ha resuelto a favor de la absolución del reo respecto del crimen de suicidio, por la ausencia de prueba plena inculpatoria y por haber vencido el argumento de la causa de tedio vital del suicidio en virtud del estado de enajenación mental que padecía el reo, y de su reputación como hombre entendido y discreto. De alguna forma se está oponiendo el rigor jurídico de la sentencia dictada por el vicario general de la villa a la arbitrariedad del juez local con su sentencia contraria al Derecho y a las leyes del Reino:

«[...] y cuando se ahorcara el dicho Juan López antes y al tiempo que había aparecido muerto estaba loco y furioso y fuera de su juicio natural $[\ldots]$ a que de su parte decía y hacía cosas por las que claramente había mostrado estar fuera e sin juicio y más siendo como era y había sido el dicho Juan López todo el discurso de la vida hombre muy entendido y discreto y por lo cual conocido e tenido en la dicha villa de Talavera e su comarca, e porque por lo susodicho así el juez eclesiástico que había conocido en la dicha relación sobre dar eclesiástica sepultura al cuerpo del dicho Juan López por su sentencia le había mandado dar y se la había dado porque cuando

Ibid., fol. 11.

Ibid., fols. 29-30. 
lo susodicho cesara que no cesaba que no era aquel caso tal por que por él conforme a derecho e leyes de estos nuestros reinos se incurría en confiscación perdimiento de bienes [...] de la cual dicha petición por los dichos nuestros alcaldes le fue mandado dar traslado a la otra parte y por el mismo pedimento cierta sentencia por el licenciado Miguel González, vicario general de la dicha villa dada en que manda enterrar el cuerpo del dicho Juan López de Uceda en lugar sagrado e cierta información recibida cómo se había enterrado en cumplimiento de la dicha sentencia el dicho cuerpo e

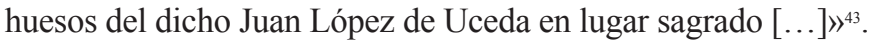

Sin embargo, la acusación no considera que la decisión de la justicia eclesiástica deba condicionar el procedimiento secular, ni que constituya una prueba efectiva en él:

«[...] e porque no hacía por él cosa alguna haberle mandado enterrar en sagrado después de haber estado en el campo muchos días muerto, porque para esto bastaba cualquier probanza e la que se había hecho no había sido conveniente $[\ldots]\rangle^{44}$.

Parece que el promotor fiscal tiende a infravalorar el proceso inquisitivo sustanciado por las autoridades eclesiásticas al haber inadvertido las evidencias que a su juicio demuestran el crimen de suicidio y haberse apoyado en otras pruebas no concluyentes. Con esta opinión, la acusación considera que el fallo dictado por el vicario general ordenando la sagrada sepultura debe quedar en un segundo plano.

\subsection{Testimonios, notoriedad y otras pruebas}

El valor de la prueba testifical en el proceso ha tenido que ser relativo, y aunque conste que se haya realizado una información de testigos, en la fase sumaria, lo cierto es que aquélla no parece haber tenido una gran relevancia, y mucho menos por encima de la comprobación del cuerpo del delito, que es cuando los testigos han estado presentes ante los resultados criminales que el juez ha acudido también a verificar personalmente:

«[...] sobre lo cual dijo hacía cabeza de proceso para averiguar la verdad de lo susodicho sobre lo cual por el dicho alcalde mayor se recibió cierta información de testigos $[\ldots] \gg\rangle^{45}$.

En el juicio plenario, y concretamente en la fase probatoria, se detalla que la defensa presenta tanto pruebas testificales como documentales a favor del reo. Dichas pruebas no son especificadas en la ejecutoria, así como tampoco se concreta su valor probatorio, pleno o semipleno:

«[...] después de lo cual el dicho pleito fue concluso y las partes recibidas a prueba en forma con cierto término dentro del cual por las dichas partes fueron hechas ciertas probanzas por testigos y escrituras por parte del dicho Diego López $[\ldots] \gg^{46}$.

\footnotetext{
Ibid., fols. 29-30.

Ibid., fol. 31 .

Ibid., fol. 3 .

Ibid., fol. 28.
} 
A raíz del recurso de apelación presentado por la parte acusada ante la Real Chancillería de Valladolid, el fiscal hace hincapié en la plenitud de las pruebas presentadas que, a su juicio, evidencian el ahorcamiento de Juan López de Uceda. Además, en un momento determinado la acusación apunta en el proceso algunas causas de tacha, denunciando que los testigos presentados por la parte acusada son de escasa fiabilidad: menores de edad, allegados (amigos y criados) y dadivados que, inducidos, habrían declarado a favor del reo. El fiscal trata así de anular la credibilidad de las pruebas presentadas por la defensa, pues, conforme a sus argumentos, la mera comprobación del cuerpo del delito sería suficiente para probar que Juan López cometió un crimen de suicidio y, consiguientemente, cualquier prueba presentada por la acusación, aun de escaso valor probatorio, solo tendría un complementario sentido confirmador del homicidio cualificado:

«[...] dijo [en referencia al fiscal] que por nos mandado verse el proceso de la causa hallaríamos la sentencia en él dada por la justicia de la dicha villa ser justa e deberse confirmar por lo siguiente e general e porque estaba probado con muchos testigos e otras pruebas concluyentes el haberse el dicho Juan López de Uceda ahorcado [...] porque para esto bastaba cualquier probanza e la que se había hecho no había sido convincente ni con testigos fidedignos ni mayores de toda erección e para quitarle de la pena de él habían de ser los testigos tales cuales dichos tenía e no debidos amigos e allegados en casa del dicho Diego López [...] e porque el delito estaba plenamente probado con muchos testigos e otras pruebas convincentes e porque además de serlo así era cosa notoria haber el sobredicho Juan López ahorcado desesperando de la misericordia de Dios y el decir era melancólico e falto de juicio e las otras cosas que por la dicha parte contraria se alegaban era todo falso e probado todo con testigos dadivados e criados del padre del dicho Juan López los cuales después que habían dicho, sus dichos se habían publicado habían

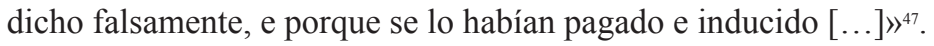

Para el fiscal, el suicidio es notorio, y a partir de este dato el resto de pruebas absolutamente secundarias. No es que el ahorcamiento de Juan López tenga una notoriedad reconocida en función de la voz pública que formaría la multitud de vecinos que presenciaron el cadáver del sujeto ahorcado; es más bien que la comprobación del cuerpo del delito demuestra notoriamente un suicidio y el resto de las pruebas sólo pueden servir para la ratificación de este diagnóstico pericial y judicial.

Ante la sentencia absolutoria de vista el promotor fiscal interpondrá en última instancia un recurso de súplica ante la Real Chancillería de Valladolid. Sabemos entonces que ninguna de las partes procesales practica nuevas pruebas, lo que permite entender que todas las consideraciones anteriores discurrían sobre la plenitud de los datos e información relevantes para el caso:

«[...] fue mandado dar traslado a la otra parte y el dicho pleito fue concluso, e las partes recibidas a prueba en forma con cierto término dentro del cual por ninguna de las dichas partes no fueron hecha probanza alguna y el dicho pleito fue concluso $[\ldots]\rangle^{48}$. 


\section{Las sentencias}

Cuando el promotor fiscal interponga recurso de súplica ante la Real Chancillería, este órgano judicial confirmará en revista la validez de la sentencia de vista absolutoria. Desde luego, la existencia de dos sucesivas sentencias absolutorias concede mayor peso a la valoración judicial de las circunstancias probatorias presentadas por la defensa. El argumento del estado de enajenación mental del sujeto, que probaría la incapacidad de dolo del acusado, permitiría motivar la sentencia absolutoria, acaso influida por la sentencia eclesiástica a favor de la sepultura en sagrado que presume un suicidio no doloso. Sin embargo, como la motivación de la sentencia no es expresa, también cabe sospechar una mayor influencia del respeto riguroso al cumplimiento de la ley, un criterio más específico de lo que parece, porque los requisitos legales para la confiscación de bienes del suicida, como la causa de conciencia de crimen o miedo de la pena una vez se ha producido la detención, la prisión o la apertura de procedimiento judicial (así como la necesaria ausencia de descendientes herederos que no excluye la interpretación extensiva favorable a los ascendientes) no se cumplen en este caso. 